\title{
Política e poder em Hobbes
}

Politics and power in Hobbes

\author{
GILMAR HENRIQUE DA CONCEIÇÃO
}

Resumo. Este trabalho procura examinar a ideia hobbesiana de busca pela estabilidade política que perpassa suas obras, fundamentado no pacto e na soberania. Como preservar o aperfeiçoamento da vida em sociedade? Isto só pode ocorrer se houver um centro estável. Argumentaremos que a estabilidade política, é dada com a figura do soberano em primeiro plano. Na primeira parte deste trabalho, apresentamos, em traços gerais, o esquema contratualista de Hobbes. Na segunda parte, sugerimos que a Soberania, a Lei Natural, a Lei Civil, bem como o exercício da Justiça e a regra da interpretação da Lei, na realidade, são fundamentos teóricos que Hobbes elabora com o intuito de garantir estabilidade à vida social, mas o medo sempre permanece (ainda que com o soberano esta paixão tenha função pacificadora).

Palavras-chave: Hobbes. Estabilidade. Direito. Contratualismo. Soberania. Legitimidade.

Abstract. This elementary work examines the Hobbesian idea of seeking political stability that permeates his works, based on the pact and sovereignty. In fact, in a world where each is master of himself (and there is no institutionalization of laws), is characterized as a world war of all against all. War implies the destruction of civilization, culture, art and science. How to preserve the improvement of life in society? This can only occur if there is a stable center. We argue that political stability is given to the sovereign figure in the foreground. In the first part of this work, we present, in general terms, the contractualist scheme of Hobbes's state of nature and the artificial creation of the Political State. In the second part, we suggest that the Sovereignty, Natural Law, Civil Law, as well as the exercise of justice and the rule of interpretation of the law, in fact, are theoretical foundations that Hobbes elaborated in order to ensure stability of social life, but fear always remains (even with the sovereign this passion has pacifying function).

Keywords: Hobbes. Stability. Law. Contractualism. Sovereignty. Legitimacy.

\section{Introdução}

No estudo do pensamento de Hobbes, pesquisas apontam que o capítulo mais conceitual do Leviatã é o capítulo $\mathrm{XVI}^{2}$, onde ele trabalha os seus conceitos centrais. Por isso mesmo é o mais complexo, no sentido de que é necessário compreender este capítulo para compreender toda a obra. Refletindo sobre o problema das coisas e da vida humana, Hobbes se apoia na possibilidade de tudo explicar matematicamente, fundamentando-se na ideia de movimento. Nosso autor concebe o universo como uma massa corpórea, onde a variedade das coisas e dos acontecimentos se explica pela variedade dos movimentos que afetam as diversas partes desse corpo. Foca, sobretudo as suas reflexões para a vida moral e social

\footnotetext{
${ }^{1}$ Professor de Filosofia na UNIOESTE. Doutor em Educação pela UNICAMP com estágio pósdoutoral em Filosofia pela UFMG. E-mail: gilmarhenriqueconceicao@hotmail.com.

2 Este capítulo intitula-se: "Das pessoas, autores, e coisas personificadas".
} 
(HOBBES, 2005). Hobbes caminha na contramão da tradição filosófica e a escolástica, divergindo, especialmente, da concepção aristotélica de natureza humana. O conceito de 'povo', desde os gregos indica que um povo sempre é preexistente ao Estado. Ora, Hobbes rompe com isso; para ele povo é uma construção artificial: não realiza nada. Não há povo antes do soberano. Consequentemente em Hobbes não temos cidadãos, e sim súditos. O real concreto é o indivíduo. De modo que faz sentido a interpretação de que o 'pai do liberalismo' talvez não seja Locke, mas Hobbes.

$\mathrm{Na}$ realidade, em termos da ideia de representação temos dois modelos: Aristóteles (coletivo) ${ }^{3}$ e Hobbes (individual). Assim, no caso do representante ser constituído por muitos homens, a voz da maioria deverá ser considerada a voz de todos eles. De acordo com Hobbes, a ideia de representação articula-se com a ideia de portador da pessoa de outrem, ou que atua em seu nome. Como multidão não é 'um', mas 'muitos', ela não poder ser tomada por um só, e sim por muitos autores, de cada uma das coisas que o representante afirma ou realiza em seu nome; visto que cada um transfere ao seu representante comum a sua própria autoridade em particular. Ocorre dessa maneira que a cada um pertencem todas as ações praticadas pelo representante (HOBBES,). A única forma de instituir um tal poder comum, que seja capaz de manter os homens em segurança, é que todos conferiram a sua força e poder a um homem (ou a uma assembleia de homens), que possa reduzir todas as suas vontades, por pluralidade de votos, a uma só vontade, que dará estabilidade ao corpo social. Para Hobbes, a multidão como unidade numa só pessoa, denomina-se República. Estamos nos referindo ao pacto recíproco, de submissão, de transferência do direito de governar a si mesmo; transferidos irrevogavelmente ao soberano. Daí que poder político passa a ser relação de comando-obediência, pois a legitimidade vem de baixo e o comando vem de cima. Porquanto, com a celebração do pacto surge a sociedade política organizada, expressa na pessoa do soberano, que é aquele que possui os poderes necessários para proteger a vida social contra a violência. O poder do soberano é ilimitado e o poder do súdito de obedecer é limitado. Limitado porque o limite do súdito é o de permanecer vivo.

O pensamento hobbesiano é um pensamento de crise social ${ }^{4}$, e de busca de sua superação, mediante o estabelecimento de um centro decisivo de poder. Em sua

\footnotetext{
3 Conforme o Estagirita, a "cidade ou a sociedade política" é o "bem mais elevado" e por isso os homens se associam em células, da família ao pequeno burgo, e a reunião desses agrupamentos resulta na cidade e no Estado ("Política", cap.I, Livro Primeiro).

4 Renato Janine Ribeiro escreve que: "O medo, gêmeo de um pensador, marcando-o desde o nascimento, enlaçado a ele feito herança ou gene, como seu direito ou natureza; a vida e a obra de Hobbes são pontuadas por esta paixão" (RIBEIRO, 1999, p. 16).
} 
Epístola ao Leitor 5 , Hobbes deixa claro as bases de seu pensamento e adianta que a filosofia que apresenta não é a do tipo que produz pedras filosofais, nem a do tipo que se encontra nos códices metafísicos: "Ela [sua filosofia] é, sim, aquela que constitui a razão natural do homem, percorrendo diligentemente de alto a baixo as criaturas e retornando com um relato verídico de sua ordem, causas e efeitos" (HOBBES, 2005). O racionalismo, o materialismo, o nominalismo, o mecanicismo e o naturalismo influenciaram Hobbes na definição dos conceitos referentes ao Estado, bem como na estruturação de sua teoria política. Assim, chamemos a atenção para dois princípios hobbesianos do conhecimento: o empirismo e o racionalismo, visto que o problema do poder é abordado em todos os níveis da filosofia física, antropológica ou política. Hobbes diferencia o poder em potentia e potestas. ${ }^{6} \mathrm{~A}$ ideia de ciência do homem como ciência do poder organiza toda a obra de Hobbes, onde não há verdades inatas; é uma obra do homem, cujo objeto é o homem.

Foi o contexto em que viveu Hobbes que lhe lançou desafios teóricos. Evidentemente, a riqueza e o vigor do pensamento deste pensador gera as mais divergentes interpretações, nestas se explicitando e se renovando para além do próprio tempo em que viveu Hobbes (CONTI, 2010). O exercício deste artigo procura realçar o esforço de Hobbes em resolver problemas políticos de seu tempo e de épocas vindouras. É sabido o quanto Hobbes vivenciou períodos de agitações políticas e sociais e disso também resulta sua preocupação com a legitimidade do poder político, com a extensão da guerra e com as crises estruturais na Inglaterra, na França, na Alemanha, e em toda Europa. Para sermos mais precisos, Hobbes elabora seu pensamento em meio à passagem do Medievo para a Idade Moderna, tal como Maquiavel7 e Montaigne $^{8}$. Ainda que defenda a monarquia, Hobbes contesta o

\footnotetext{
${ }^{5}$ HOBBES, Th. Elementos de Filosofia - Primeira Seção - Sobre o Corpo. Parte I - Computação ou Lógica. Tradução e apresentação de José Oscar de Almeida Marques. Campinas: IFCH/Unicamp, 2005 (Clássicos da Filosofia. Cadernos de Tradução).

${ }^{6}$ Potentia designa a potência ou a força, ou seja, capacidade de produzir ou sofrer efeitos. Essa capacidade não encerra virtualidade alguma, e a potência é sempre em si mesma um ato, mas cujos efeitos dependem das condições exteriores. Potestas designa a potência investida do direito, ou seja, a princípio o poder político; esse poder não é natural, mas artificial. (HUISSMAN, p. 505).

7 Montaigne é leitor de Maquiavel, e com ele estabelece muitas afinidades (CONCEIÇ̃̃O). O pensamento político de Maquiavel deveria ser situada a meio caminho entre a Idade Média e a modernidade: por um lado, diferentemente das doutrinas medievais, renuncia a qualquer finalidade ético-religiosa em relação à comunidade política; por outro lado, porém, não se concentra sobre o indivíduo, como o farão Hobbes, Locke, Kant entre outros (AMES, p. 295, 2011).

8 Curiosamente, há uma passagem no capítulo XIV do Leviatã, quando Hobbes se refere à necessidade de cumprir os pactos aceites por medo, que é textualmente bem parecido com o que escreve Montaigne acerca da promessa feita a bandidos por medo. Comentando esse tópico, escreve Montaigne que também aos bandidos é preciso cumprir a palavra dada, pois o cumprimento da palavra empenhada não depende do valor moral da pessoa a quem foi feita a promessa: "Ladrões aprisionaram-vos; voltaram a libertar-vos, tendo obtido de vós o juramento de pagardes determinadas soma; é errado dizer que um homem de bem estará desobrigado de sua palavra sem pagar, estando fora das mãos deles. Não é assim. O que o medo uma vez me fez querer, sou obrigado a continuar querendo sem o medo, e mesmo que ele tenha forçado apenas minha língua sem a
} 
chamado direito divino que era utilizado para justificar as monarquias europeias. $\mathrm{O}$ soberano, em Hobbes não está legitimado por um poder divino ou transcendental para governar sob suas idiossincrasias pessoais, mas pela transferência da vontade e poder de agir na defesa da ordem estabelecido como um poder centralizado e dotado de força, pela lavratura consuetudinária do contrato social. Em Hobbes a sociedade é organizada pelo Leviatã, (uma pessoa jurídica e abstrata) que se concretiza em um governo constituído, seja por uma monarquia (como prefere Hobbes) seja por uma aristocracia, seja por uma democracia. Porém, Hobbes julga que democracia é a ausência de governo e que não se pode classificar a anarquia como uma espécie ou forma de governo.

Logo nas primeiras linhas do capítulo XIII do Leviatã, Hobbes escreve que a natureza fez os homens tão iguais, quanto às faculdades do corpo e do espírito (HOBBES, 1983, p. 74). Portanto, em razão desta igualdade, quando dois homens desejam a mesma coisa, ao mesmo tempo, tornam-se inimigos. Esta é uma realidade de desconfiança de uns em relação aos outros. Outro detalhe que chama a atenção é que Hobbes discorda da ideia de sociabilidade natural dos seres humanos: "Por outro lado, os homens não tiram prazer algum da companhia uns dos outros (e sim pelo contrário, um enorme desprazer), quando não existe um poder capaz de manter a todos em respeito" (HOBBES, 1983, p. 75). A natureza dissociou os homens, tornando-os capazes de atacar-se e destruir-se. Em seguida, Hobbes aponta as três causas mais importante de discórdia entre os homens: competição, desconfiança e glória. Entregues em tal realidade instável, não há nada de duradouro socialmente que possa ser mantido. Ou seja, a insociabilidade e as causas de discórdia requerem um poder capaz de manter a todos em respeito, porque nada mais miserável que um Estado onde civilização alguma, paz alguma, são possíveis:

Numa tal situação não há lugar para a indústria, pois seu fruto é incerto, pois seu fruto é incerto; consequentemente não há cultivo da terra, nem navegação, nem uso das mercadorias que podem ser importadas pelo mar; não há construções confortáveis, nem instrumento para mover e remover as coisas que precisam de grande força; não há conhecimento da face da Terra, nem cômputo do tempo, nem artes, nem letras; não há sociedade; e o que é pior do que tudo, um constante temor e perigo de morte violenta. E a vida do homem é solitária, pobre, sórdida, embrutecida e curta (HOBBES, 1983, p. 76).

vontade, ainda assim sou obrigado a fazer de minha palavra mealha certa. Quanto a mim, quando por vezes ela irrefletidamente ultrapassou meu pensamento, tive escrúpulo em renegá-la" (III, 1, p. 22). Claro, Montaigne não se refere a pacto. 
Em tal realidade, nada pode ser injusto, não há bem e mal, nem justiça e injustiça, nem muito menos o 'meu' e o 'teu', pois se trata de guerra de todos os homens contra todos os homens. Onde não há poder comum não há lei, e onde não há lei não há injustiça. Desse modo, a fim de viverem em paz uns com os outros e de serem protegidos surge a necessidade de que os homens concordem e pactuem, cada um com cada um dos outros, que a qualquer homem ou assembleia de homens a quem seja atribuído pela maioria o direito de representar a pessoa de todos eles. Portanto, todos deverão autorizar todos os atos e decisões desse homem (ou assembleia de homens) tal como se fossem seus próprios atos e decisões (HOBBES, 1983, p. 107). Trata-se da instituição do Estado: "é desta instituição do Estado que derivam todos os direitos e faculdades daquele ou daqueles a quem o poder soberano é conferido mediante o consentimento do povo reunido" (HOBBES, 1983, p. 107).

Com Hobbes, o conceito de autorização será determinante no curso da história. A renúncia do súdito cria a autorização do súdito ao soberano, de modo que se deve querer o que o Estado quer. Quem não proceder assim deverá ser punido pelo soberano. Mas, o fundamento do direito de punir não se encontra nas renúncia, nem na transferência. Na realidade, o direito de punir nasce com a autorização da invenção do soberano. Tudo isso pelo fato de que os pactos, para Hobbes, tem como fundamento a espada.

Conforme Oliveira (2012), Hobbes discorda das ideias costumeiras acerca do fundamento divino ou natural da sociedade, destacando a centralidade do indivíduo, fundamentando a legitimidade da constituição do Estado moderno na realização de um duplo contrato: entre os indivíduos que constituem a sociedade e destes com o soberano. Este duplo contrato possibilita a secularização do fundamento do poder, a legitimação racional do estabelecimento de um conjunto de prerrogativas do soberano e de deveres dos súditos. Porém, se buscarmos o capítulo XVII do Leviatã, objetivando verificar até que ponto essa hipótese de 'duplo contrato' se sustenta, quer nos parecer que Hobbes não admite um duplo contrato no sentido colocado. Dentre os deveres dos súditos está o de obedecer às ordens do soberano (por meio das leis civis) e de se comportar conforme o contrato. No que tange às prerrogativas do soberano, a principal é que ele pode fazer valer o direito, mesmo nas situações em que haja resistência. Considera que este é o custo a ser pago pelos súditos para ter estabilidade social, mediante uma vida segura e pacífica no Estado. Deste fato surge o direito de punir, que se justifica na medida em que é utilizado para a proteção do bem comum, para a preservação de todos e evitar a desestabilidade e a volta ao estado de natureza.

\section{Hobbes e o corpo social}


Hobbes teve uma formação refinada, conheceu os pensadores clássicos e sabia grego e latim. Bem jovem, ainda, foi admitido como estudante na Universidade de Oxford, onde dedicou-se à lógica e à filosofia. Tinha interesse também por física, o que o levou a estudar obras de Galileu, Kepler e Euclides. Todos estes elementos teóricos aparecem em seus escrito. Como 'mecanicista', considera que as pessoa são seres de matéria e movimento, por isso submetem-se às mesmas leis da natureza que os objetos físicos. A explicação mecanicista do universo de Hobbes, opunha-se à interpretação teleológica aristotélica e escolástica. Hobbes diverge da concepção aristotélica do zoon politikon, que entendia o homem como um animal político (HOBBES, 1983, p. 25-26). Argumenta que a disposição natural do homem não é para a vida harmônica em sociedade, longe disso: é regida pelo egoísmo e pela busca de autopreservação. Do mesmo modo, contrariamente à tradição aristotélicamedieval, (que considerava que o ser humano era naturalmente político ou social), Hobbes argumenta que o homem só busca companheiros por interesse, ou necessidade, consequentemente, a sociedade política é o fruto artificial de um pacto voluntário ${ }^{9}$, de um cálculo de interesse.

A única realidade natural e tangível é o indivíduo que deve ser estudado em sua natureza e na dinâmica de suas paixões. Hobbes escreve que somente podemos conhecer algo do mundo exterior a partir das impressões sensoriais que recebemos dele. De acordo com Hobbes o conhecimento vem por meio dos sentidos, sendo que a paixão é mais forte que a vontade. Segundo ele, a paixão tem duas formas fundamentais; a tendência e aversão (amor e ódio). Dessa maneira, como na vida em sociedade nos encontramos envolvidos numa rede de influências, umas favoráveis, outras hostis. As reações das nossas paixões constituem uma luta de potência. Destarte, Hobbes compara a nossa vida a uma corrida em que o nosso fim e a nossa recompensa seria ultrapassar os nossos concorrentes, em diversos movimentos de paixões:

Esforçar-se, é desejo. Afrouxar, é sensualidade. Considerar os que vem atrás de nós, é glória. Considerar os que vão adiante, é humildade. Perder terreno olhando para trás, é vanglória. Ficar retido, é ódio. Voltar sobre os seus passos, arrependimento. Manterse em folego, é esperança. Estar cansado é desespero. Esforçar-se por atingir o mais próximo, é emulação. Suplantá-lo ou lança-lo por terra é inveja. Resolver-se a transpor um obstáculo imprevisto, é cólera. Transpor um obstáculo com facilidade galharda, é grandeza de ânimo. Recuar perante pequenos obstáculos, é pusilanimidade. Cair de improviso, é disposição para chorar. Ver cair outrem, é disposição para rir. Ver ultrapassar alguém contra nossa vontade, é compaixão. Ver que tomam a dianteira contra a nossa vontade, é

\footnotetext{
9 Por meio do pacto (em que cada um renuncia ao governo de si mesmo) foi criado o Estado: "cedo e transfiro meu direito de governar a mim mesmo a este homem, ou a esta assembleia de homens, com a condição de que transfiras a ele teu direito, autorizando de maneira semelhante todas as suas ações" (HOBBES, 1983, p. 82).
} 
indignação. Ligarmo-nos a alguém é amor. Impelir para diante de nós aquele a quem nos ligamos, é caridade. Ferir-se por precipitação, é vergonha. Ser continuamente ultrapassado, é miséria. Ultrapassar continuamente o que vai adiante, é felicidade. Abandonar a corrida, é morrer (THONNARD, 1968, P. 544-45).

Na mesma direção deve-se evitar a ingratidão, os ultrajes, o orgulho que tornam extremamente difíceis a concórdia, sempre recorrendo a um árbitro imparcial e desinteressado. No âmbito da moral e da política, sua ideia pode ser anunciada do seguinte modo: os súditos do Estado são individualistas e só se juntam em comunidade por entenderem que esse é o melhor meio de sobrevivência. Todavia, ainda que convencional, o Estado sempre existiu, e a regressão ao estado de guerra só tem realidade na forma de guerra civil. O ser humano entra na ordem moral entrando na vida civil pelo pacto social, ditado pela razão para obter a paz, a justiça e a virtude moral.

Em outras palavras, Hobbes compreendia que, no acordo que viabiliza o Estado, está a manutenção da paz. A preocupação com a paz pública o impeliu a escrever, inclusive, a sua obra Leviatã, que foi escrita durante a Guerra Civil Inglesa ${ }^{10}$. O contexto de intermináveis lutas pela conquista do poder político com massacres e derramamento de sangue, leva ao terror, e à falta de segurança. De fato, esses eram os sentimentos que preocupavam a Hobbes, que entendia que sem estabilidade permanente a sociedade se destrói. O temor da morte é o primeiro motivo da busca pela paz, que consiste na sua salvação e liberdade. Porém, em tal sociedade não há justo nem injusto, visto que não há critérios, nem poder absoluto.

O conceito de 'estado de natureza', conforme Hobbes se constitui como uma guerra de todos contra todos, visto que, na ausência de uma comunidade política, todos as pessoas teriam licença para possuir quase tudo, sem limites definidos e, como não haveriam restrições, exerceriam suas paixões e desejos conforme lhes aprouvessem. A única forma de se regrar as condutas entres os seres humanos é pela força. Todavia, como vimos, em todos os lugares onde há igualdade de forças é a luta que 'resolve' os conflitos, todavia dessa luta ninguém poderá sair vitorioso. Os seres humanos são iguais em seu conjunto, ainda que haja alguém mais forte que o outro, este pode vencer pela astúcia; e são, portanto, concorrentes (e, assim, vivem em um constante estado de guerra). Os fortes e os fracos têm medo. Na realidade, a causa do medo recíproco consiste, em parte, na igualdade natural dos homens, em parte na sua mútua vontade de se ferirem - do que decorre que nem podemos esperar dos outros, nem prometer a nós mesmos, a menor segurança. Esta situação

\footnotetext{
${ }^{10}$ Quando retornou à Inglaterra, Hobbes coloca-se como defensor do rei, ameaçado pela revolução liberal e escreve a este propósito, o seu primeiro tratado: The Elements of Law natutal and politic (1640). Esta obra circulou, inicialmente, em manuscrito e só foi editada em 1650, em duas partes: Human nature e De corpore político. Na realidade, trata-se de um resumo do sistema desenvolvido em dois de seus grandes livros: De Cive e De Homine. (THONNARD, 1968).
} 
inclui tanto a guerra quanto os conflitos e as dificuldades extremas em geral. Nas palavras de Hobbes:

A natureza fez os homens tão iguais, quanto às faculdades do corpo e do espírito, que, embora por vezes se encontre um homem manifestantemente mais forte de corpo, ou de espírito mais vivo do que outro, mesmo assim, quando se considera tudo isso em conjunto, a diferença entre um e outro homem não é suficientemente considerável para que qualquer um possa com base nela reclamar qualquer benefício a que outro não possa também aspirar, tal como ele. Porque quanto à força corporal o mais fraco tem força suficiente para matar o mais forte, quer por secreta maquinação, quer aliando-se com outros que se encontrem ameaçados pelo mesmo perigo (HOBBES, 1983, p. 75).

Em tal realidade, não haveria possibilidade para que as grandes realizações da humanidade fossem possíveis. Ou seja, a indústria, as grandes navegações, bem como as descobertas, a fabricação de produtos sofisticados, dependem de algum tipo de estabilidade para as transações e manutenção daquilo que se produz. Caso contrário, assombrados pelo risco constante de uma morte violenta, ou mesmo da tomada de sua produção, os homens não teriam como produzir artes, literatura ou a própria sociedade organizada. Unicamente, com a criação do Estado, por meio do pacto, se experimentará a paz e a prosperidade. Sem um centro físico que proporcione estabilidade os movimentos são caóticos.

Assim, como forma de contornar esta situação de absoluta incerteza, as pessoas aceitam o mencionado contrato social, estabelecendo assim a sociedade civil. Sociedade civil, em Hobbes, se caracteriza por uma reunião de indivíduos sob uma autoridade soberana, para a qual todos concordam em ceder direitos, ou parte de seu direito natural a toda as coisas, em troca de proteção, particularmente como meio de garantia dos acordos entre indivíduos. A caução dos acordos está na autoridade do soberano: "Àquele que é portador dessa pessoa se chama soberano, e dele se diz que possui poder soberano. Todos os restantes são súditos" (HOBBES, 1988, p. 106). Tendo em vista a estabilidade social, o Estado centraliza as decisões públicas.

\section{O Leviatã como epicentro da estabilidade social}

O Leviatã que estabelece e salvaguarda a paz comum é conforme a razão reta e, com ele, vem as noções de justo e bom, moralmente. Hobbes não vê a maldade humana como uma espécie de essência. Por isso é importante salientar que o 'realismo' hobbesiano não pode ser confundido com 'essencialismo'. Não é a natureza, mas as condições de existência em estado de natureza que tornam o homem tal como vem sendo. Em razão do interesse em garantir a sobrevivência de cada um, os homens no estado de natureza se uniram e firmaram um pacto de 
submissão com a intenção de transferir o direito natural individual para um terceiro que irá substituir a vontade de todos (a todos representando). Portanto, o contrato social é a origem do poder político, no qual ocorre a transmissão total dos direitos naturais absolutos dos homens a um terceiro (o soberano). Segue a isso que como a transferência dos direitos naturais ao soberano é absoluta, o poder político do soberano é uno, indivisível e indissolúvel. Como forma de garantia do poder do soberano, Hobbes argumenta que, na realidade, dois pactos foram firmados em um só momento: os homens naturais se constituem em sociedade política; ao mesmo tempo em que se submetem a um senhor. Porém a terceira parte (o soberano), não está obrigado pelo pacto, nem a ele deve se submeter, uma vez que o contrato, prevê um único pacto firmado entre os homens e não entre eles e a terceira parte. Em outras palavras, o contrato social, fundador do Estado Político, foi celebrado pelos homens entre si e não entre os homens e o soberano. De forma que soberano, goza de liberdade ilimitada ${ }^{11}$.

Em suma, o poder político, conforme Hobbes, possui quatro características: a) O poder é absoluto, uma vez que o rei, ou a assembleia de homens não estão sujeitos as leis que criam; b) O poder é concentrado (agrega o executivo, o legislativo e o judiciário); c) O poder é impositivo, para controlar todas as manifestações políticas e culturais da sociedade; d) O poder é regulador e detentor da esfera econômica.

A espada da justiça desempenha uma função importante na concepção de Estado hobbesiana, uma vez que esse tipo de artifício desarma o conflito entre os homens no que se refere ao uso das vontades particulares. Hobbes escreve que "[...] considerando que todo homem supostamente faz todas as coisas tendo em vista o seu próprio benefício, ninguém pode ser árbitro adequado em causa própria [...]" (HOBBES, 1983, p. 134). Desse modo, os conflitos entre os súditos não precisam ser resolvidos entre si por si mesmos, mas por meio da justiça. Ora, isso nada mais é do que a efetivação do desejo de viver em segurança. O medo figura entre as paixões complexas que dizem respeito ao comportamento pacífico ou belicoso dos seres humanos. Conforme Hobbes, no estado de natureza o medo é a paixão dominante, causando desordem; e a estabilidade não é possível. Porém, esse mesmo medo também se encontra na origem da sociedade, só que, nesta, o medo é a causa da ordem no estado civil, produzindo estabilidade. No estado de natureza temos o medo de todos, já no estado civil temos o medo ao soberano. Observaremos, assim, que a legitimidade do soberano (a quem se deve temer) somente se garante se ele

\footnotetext{
II "É confiado ao soberano o direito de recompensar com riquezas e honras e o de punir, com castigos corporais ou pecuniários, ou com a ignomínia, qualquer súdito, de acordo com a lei que previamente estabeleceu. Caso não haja lei estabelecida, de acordo com o que considerar mais capaz de incentivar os homens a servir a república, ou de desestimular a prática de desserviços a ela" (HOBBES, 2003, p. 154).
} 
cumprir com suas obrigações: garantir a paz e a vida social regular do Estado (HOBBES, 1983).

Consoante a isso, ainda que o pacto seja voluntário, nem mesmo o temor da morte (a que Hobbes se refere em várias circunstâncias), e a voluntariedade de defender as leis de natureza, são suficientes para garantir o necessário convívio em sociedade e o respeito ao contrato. Requer-se para isso a necessária presença da força do Estado, pois os pactos sem espadas não são mais do que palavras. Quanto 'a propriedade, do mesmo modo que ocorreu com os demais direitos naturais, a propriedade passou a ser um dos atributos da soberania e, como tal, passou a ser regulamentada pelo Estado, pelas leis do Estado. Resulta assim que a propriedade é uma relação jurídica e sua legitimação, uma emanação do poder soberano, da vontade do Estado. No que se refere à justiça, é o Estado que possui o direito de ouvir e julgar o que diz respeito às leis e aos fatos, visto que possui o monopólio da justiça.

Como se pode observar, Hobbes fundamenta a sua teoria do direito, da lei e da instituição do estado numa antropologia, pois julga que a sociedade não é mais uma totalidade natural, e sim uma realidade artificial e frágil, que depende do consentimento dos homens. Somente pode ser justo ou injusto aquilo que está sob um pacto ou uma lei. Ora, como o soberano não é parte do pacto, não está, assim, submetido a nenhuma lei. Aquilo que se denomina justiça e injustiça apenas são aplicáveis aos súditos (aqueles que participam do pacto). Por esta razão, os súditos cometem injustiça no momento em que descumprem o pacto, rompendo com a finalidade do Estado. Por sua vez, o soberano se constitui como o princípio de justiça e injustiça. Por isso mesmo, o soberano não pode ser julgado sobre se determinada ação praticada por ele foi justa ou injusta. Ele está fora do pacto e surge para julgar os súditos, defendendo a conservação do Estado e a finalidade para a qual foi criado (para garantir a paz e segurança), ou em outras palavras: a estabilidade social. Assim, o soberano está acima do pacto, e o contrato já feito não pode mais ser cancelado ${ }^{12}$. Não há legitimidade na deposição do soberano e nem em sua morte, uma vez que foram os próprios súditos que, pelo pacto, transferiram a ele seus direitos, assumindo dessa forma, como seus todos os seus atos. Nesta direção, o súdito que agir para punir o soberano, na realidade, estará castigando a si e aos outros por seu ato. Institucionalmente todos os súditos são autores de tudo aquilo seu soberano fizer. Entretanto, existem algumas liberdades que os súditos não transferem pelo pacto. Por exemplo: o direito de autodefesa:

${ }^{12} \mathrm{O}$ pacto de fundação do Estado Político é irreversível não somente para os homens que o celebraram, mas também para o próprio soberano: "dado que o direito de representar a pessoa de todos é conferido ao que é tornado soberano mediante um pacto celebrado apenas entre um e cada um, e não entre o soberano e cada um dos outros, não pode haver quebra do pacto da parte do soberano, portanto nenhum dos súditos pode libertar-se da sujeição, sob qualquer pretexto de infração" (HOBBES, 1983, p. 108). 
Os pactos no sentido de cada um abster-se de defender seu próprio corpo são nulos. [...] Ninguém fica obrigado pelas próprias palavras a matar-se a si mesmo ou a outrem. Por consequência, que a obrigação que às vezes se pode ter por ordem do soberano, de executar missão perigosa ou desonrosa [...] quando nossa recusa de obedecer prejudica o fim em vista do qual foi criada a soberania, não há liberdade de recusas; mas, caso contrário, há essa liberdade (HOBBES, 1983, p. 133).

Em razão disto, um ato de resistência que atente contra o direito à vida do súdito não constitui, per se, uma injustiça visto que, neste caso, não se está violando o pacto de autorização. Ou seja, o súdito está agindo simplesmente no plano da lei de natureza, e a justiça e injustiça só têm validade em relação à lei civil. De fato, o Estado tem uma causa jurídica (a cessão dos direitos de cada um para o soberano), o que não significa que as pessoas estejam por esta razão desprovidos de direitos. Já mencionamos que o Estado deve garantir a segurança, a estabilidade e a paz, e, se isto não for feito, as pessoas recuperarão o direito natural de proteger-se e defender-se com suas próprias forças. Ou seja, tudo o que o soberano faz não é ipso facto legítimo, e a própria justiça não teria mais sentido se o soberano não agisse em conformidade com a justa razão, seguindo as prescrições das leis naturais.

\section{Considerações finais}

Resgatemos, portanto, a ideia nuclear que percorre este trabalho: apresentar a maneira com que Hobbes teoriza o Estado como necessário para a estabilidade social. Salientamos, aí, que a ideia de soberania é o fundamento da ordem pensada por Hobbes. É o soberano que cria a ordem social e que lhe garante a estabilidade. Ou seja, é necessidade de um Estado soberano como forma de manter a paz civil que acompanha a reflexão hobbesiana. Portanto, o Leviatã surgiu do acordo de vontades entre os homens para garantir a paz e a defesa de todos, sem o qual pereceriam.

Observamos que, em Hobbes, povo somente existe 'no' e 'pelo' soberano. Concretamente, o que existe são indivíduos, por isso aquilo que funda a unidade é o soberano. O que existe antes do Estado é uma multiplicidade de indivíduos; não há comunidade política.

De acordo com Hobbes, as paixões que nos guiam são o medo e a esperança, portanto se constituem em motivações capazes de dar vida à sociedade civil. Assim sendo, o Estado mobiliza tais sentimentos pela lei e pelo controle, uma vez que o indivíduo não reconhece o direito do outro, ignorando o princípio da reciprocidade. É este o sentido da necessidade do Estado: como somos incapazes de regular a nós mesmos surge o Leviatã para criar regras e punir, objetivando preservar a estabilidade social. Porquanto, como o soberano pode empreender qualquer ação 
para preservar o bem público, ele não comete injúria. Mais ainda: mesmo afrontando a lei, o soberano não comete injustiça ${ }^{13}$. Quem é livre não é o indivíduo, mas o Estado. Ou melhor, a liberdade dos súditos está no direito, e todos os direitos vêm da autorização. Como vimos, pacto é autorização. Assim, a liberdade dos súditos consiste em fazer aquilo que a lei não proíbe.

Hobbes articula os desejos satisfeitos, ou que buscam por sua satisfação, (mas, que não pode ser plenamente e para sempre satisfeitos) ao desejo de poder. Além disso, poder entre os homens suscita oposição, visto que a competição pela riqueza, pela honra, pelo mando e por outros poderes conduz à luta, à inimizade e à guerra (HOBBES). Conforme Hobbes, a felicidade é o fim de todo homem, mas nunca é um momento estável e sim como resultado de apetites, desejos e inclinações satisfeitos. Porém, ser feliz é poder usufruir, gozar, ter prazer em algum momento:

A felicidade é um contínuo progresso do desejo de um objeto para outro, não sendo obtenção do primeiro outra coisa senão o caminho para conseguir o segundo. Sendo a causa disto que o objeto do desejo do homem não é gozar apenas uma vez, e só por um momento, mas garantir para sempre os caminhos de seu desejo futuro. Portanto, as ações voluntárias e as inclinações dos homens não tendem apenas para conseguir, mas também para garantir uma vida satisfeita, e diferem apenas quanto ao modo como surgem, em parte da diversidade das paixões em pessoas diversas, e em parte das diferenças no conhecimento e opinião que cada um tem das causas que produzem os efeitos desejados (HOBBES, 1983, p. 6o).

Lembremos que Hobbes disseca as paixões humanas, notadamente o desejo de poder, e a competição entre os homens. Na lógica de Hobbes, em termos de estabilidade social, a religião ocupa função importante na coesão do Estado, evitando a guerra civil. Claro, a religião subordina-se ao soberano, nos assuntos mundanos, ou seja Hobbes requer a subordinação da religião ao Estado. Argumenta que como o Estado é a forma encontrada para cessar o permanente estado de guerra de todos contra todos, a presença de vários soberanos gera necessariamente as competições e perturba a paz. Como para Hobbes, a Igreja cristã não passa de uma sociedade civil formada por cristãos, também ela deve estar submetida ao soberano. De maneira que é o Leviatã que tem a autoridade, mesmo em matéria de culto, de hierarquia e de dogma religioso: nomeia os bispos, determina a liturgia, e resolve as

\footnotetext{
${ }^{13}$ Escreve Hobbes: "Dado que todo súdito é por instituição autor de todos os atos e decisões do soberano instituído, segue-se que nada do que este faça pode ser considerado injúria para com qualquer de seus súditos, e que nenhum deles pode acusá-lo de injustiça. Pois quem faz alguma coisa em virtude da autoridade de um outro não pode nunca causar injúria àquele em virtude de cuja autoridade está agindo. Por esta instituição de um Estado, cada indivíduo é autor de tudo quanto o soberano fizer, por consequência aquele que se queixar de uma injúria feita por seu soberano estarse-á queixando daquilo de que ele próprio é autor, portanto não deve acusar ninguém a não ser a si próprio; e não pode acusar-se a si próprio de injúria, pois causar injúria a si próprio é impossível" (HOBBES, 1983, p. 109).
} 
controvérsias doutrinais. Tal é, conforme Hobbes, o único meio de estabelecer a paz, fim supremo do Estado: Salus Populi suprema lex ${ }^{14}$.

Finalmente, ao longo deste nosso texto, nesta espécie de mecanismo universal que constitui o pensamento de Hobbes oferecemos, como recurso metodológico, uma espécie de eixo que denominamos 'estabilidade'. Esta noção é fundamental no sentido de pensar uma ordem social. Qualquer estabilidade pode sustentar ou equilibrar uma dada sociedade? Entretanto, sem estabilidade, nenhuma sociedade se mantém. Hobbes argumenta que até mesmo o reino das trevas tem sua ordem: no reino de Satanás ${ }^{15}$, aparece a soberania de Belzebu.

Voltemos, porém, para o nosso mundo. No caso da sociedade civil pensada por Hobbes temos o leviatã. Como chamamos a atenção, Hobbes compara o Estado a um ser humano artificial, criado para proteção e defesa da sociedade. Quem quiser pode conferir, lendo a descrição minuciosa do corpo social, feita por Hobbes, no início do livro Leviatã.

O pacto tem tamanha importância no pensamento hobbesiano acerca da estabilidade que ele a compara ao Fiat do logos divino. Se, no paraíso, foi criado o homem, com o pacto foi criado o Estado. Hobbes vê como uma doença tudo aquilo que ameaça a estabilidade do Estado. Se a dissolução do estado não implica, necessariamente, no retorno ao estado de natureza, ao menos implica no fato de que ninguém mais está obrigado ao pacto. Pois, se a passagem do estado de natureza para o estado civil acontece de fato e de direito, a regressão do segundo para o primeiro, sempre possível, de fato, é impossível de direito (HUISMAN, 2001). Seja como for, com isso não temos mais estabilidade e a sociedade desmorona.

Em outras palavras, se o Estado preservar a segurança de todos, cada pessoa se torna livre para fazer o que bem entender em sua vida privada (HOBBES, 1983). Na realidade, a teoria hobbesiana combate a força social que surge no Estado moderno e que leva a Europa para a guerra: indivíduos que buscam tão somente seus interesses materiais particulares e que são expressos pela burguesia (que se torna cada vez mais poderosa e que parece desagregar perigosamente os fundamentos da vida em sociedade). Dessa forma, não é mais o indivíduo que existe em função do Estado, mas, ao contrário, é o Estado que deve existir em função do indivíduo. Assim, Hobbes acaba fundamentando o poder político a partir de uma lógica instrumental individualista própria do novo espírito burguês nascente, apesar de reagir, em termos políticos, contra esse novo espírito. A base do poder político e das

\footnotetext{
${ }^{14 " S e j a ~ a ~ s a l v a c ̧ a ̃ o ~ d o ~ p o v o ~ a ~ l e i ~ s u p r e m a ": s i g n i f i c a n d o ~}$ que todas as leis particulares devem ter em vista o bem .coletivo. in Dicionário Priberam da Língua Portuguesa [em linha], 20082013, https://www.priberam.pt/dlpo/salus\%2opopuli\%2osuprema\%2olex\%2oesto [consultado em 2009-2016].

${ }^{15}$ Cfr.: PARTE 3 - DO ESTADO CRISTÃo e PARTE 4 - DO REINO DAS TREVAS, do livro LEVIATÂ.
} 
relações sociais não é o respeito ao próximo (moral); o temor a Deus (religião); os interesses nacionais (razão de Estado); a honra (códigos da nobreza), mas sim o interesse próprio, o bem-estar e a segurança de cada indivíduo na esfera da vida privada (utilidade) (YAMAUTI, 2001).

\section{Referências}

AMES, J. L. A formação do conceito moderno de Estado: A contribuição de Maquiavel.

Discurso. 2011, p. 293.

CONCEIÇÃO, G. H. Montaigne e a política. Cascavel: Edunioeste, 2014.

CONTI, R. Liberdade para além do Estado em Thomas Hobbes. São Paulo, USP, 2010 [Tese de Doutorado].

HOBBES, T. Leviatã ou a matéria, forma e poder de um estado eclesiástico e civil. $4^{a}$ ed. São Paulo: Nova Cultural, 1988.

Do cidadão. São Paulo : Martins Fontes, 2002.

. Leviatã. Tradução de João Paulo Monteiro; Maria Beatriz Nizza da Silva. São Paulo:

Martins Fontes, 2003.

. Elementos de Filosofia - Primeira Seção - Sobre o Corpo. Parte I - Computação ou

Lógica. Tradução e apresentação de José Oscar de Almeida Marques. Campinas:

IFCH/Unicamp, 2005 (Clássicos da Filosofia. Cadernos de Tradução).

. Os Elementos da Lei Natural e Política. Tradução de Bruno Simões. São Paulo:

Martins Fontes, 2010.

HUISMAN, D. Dicionário dos filósofos. Trad. Claudia Berlinder, Eduardo Brandão, Ivone Castilho Benedetti, Maria Ermantina Galvão. São Paulo: Martins Fontes, 2001.

JANINE RIBEIRO, R. Ao leitor sem medo: Hobbes escrevendo contra o seu tempo. Belo Horizonte: Editora UFMG, 1999.

OLIVEIRA, F. A. S. O direito de punir em Thomas Hobbes. Ijuí, RS: Edunijuí, 2012.

MONTAIGNE, M. Os Ensaios. Trad. Rosemary Costhek Abílio. São Paulo: Martins Fontes, 2001, 2002, 2006. (Coleção Paidéia). 3 v.

THONNARD, A. A. Compendio de História da Filosofia. 2 o Vol. Trad. Manuel Antonio Valente Pombo. São Paulo: Herder, 1968.

YAMAUTI, N. N. A teoria política hobbesiana. Urutagua, Maringá, ano I, n. 1, maio 2001. Disponível em: <http://www.urutagua.uem.br//ruo2_politica.htm>. Acesso em: 22 de jul. 2001.

Submissão: 11.07.2017 / Aceite: 10. 08.2017. 